\title{
Evolución económica de las provincias argentinas durante la Belle Époque (1880-1913). Un análisis a través de los recursos fiscales
}

\author{
Economic evolution of the Argentine provinces during the Belle Époque \\ (1880-1913): an analysis of fiscal resources
}

\author{
Gerardo Sánchez \\ Doctorando en Historia \\ Universidad de Buenos Aires, Buenos Aires - Argentina \\ https://orcid.org/0000-0002-3744-8680 \\ gadi82@yahoo.com.ar
}

Fecha de recepción: 16 de noviembre de 2016

Fecha de aceptación: 01 de marzo de 2017

Sugerencia de citación: Sánchez, G. (2017). Evolución económica de las provincias argentinas durante la Belle Époque (1880-1913). Un análisis a través de los recursos fiscales. tiempo\&economía, 4(2), 89-112, en prensa, doi: http://dx.doi.org/10.21789/24222704.1223

\section{RESUMEN}

Las últimas décadas del siglo XIX y las primeras del siglo XX fueron, sin duda, de gran crecimiento económico para Argentina. Aun así, las numerosas investigaciones sobre este periodo han profundizado muy poco en el diverso grado de participación de las distintas provincias y el impacto que tuvo dicho proceso en cada una de ellas. Incluso, las veces que se incorporó esta arista, se ha hecho desde una óptica muy simplificadora en la que se distingue solamente el interior del litoral. En este trabajo se identifica, a través de un análisis detallado de las finanzas públicas, las distintas performances económicas provinciales. Como resultado de este análisis, se capta la heterogeneidad de casos, dentro de un marco general de crecimiento económico, enriqueciendo el análisis del periodo más allá de la clásica división de interior y litoral. 
Palabras clave: desigualdades, análisis regional, crecimiento, historia económica

Códigos JEL: N01, D63, R11, O47

\begin{abstract}
The last decades of the nineteenth century and the first decades of the twentieth century were undoubtedly years of great economic growth for Argentina. Even so, the numerous investigations on this period have little depth in the diverse degree of participation of the different provinces in that process. Even the times that this element was incorporated, it has done so from a very simplifying perspective in which only the interior of the litoral is distinguished. This paper identifies, through a detailed analysis of the public finances, the different provincial economic performances. As a result of this analysis the enormous heterogeneity of cases is captured, within a general framework of economic growth, enriching the analysis of the period, beyond the classic division of interior and litoral.
\end{abstract}

Keywords: Inequality, Analysis of Regional Economies, Growth, Economic History

JEL Codes: N01, D63, R11, O47 


\section{Introducción}

No hay dudas de que para la historia económica argentina el periodo comprendido entre las últimas décadas del siglo XIX y a las primeras del siglo XX fue de gran crecimiento económico. Este desempeño, que la ubicaba entre las principales economías del mundo, inspiró una vasta producción literaria, de autores de variadas nacionalidades, que comparó la evolución de Argentina con países como Australia, Canadá y Nueva Zelanda. Estos trabajos fueron producidos, sobre todo, en la década de los ochenta, aunque su temática fue retomada en años más recientes ${ }^{1}$.

Ahora bien, cuando se analiza la producción científica sobre la época, surge un claro contraste entre la cantidad de literatura que ha destacado el desempeño del país con las producciones que analizan el diverso grado de participación de las provincias y el impacto que tuvo dicho proceso en cada una de ellas. Incluso muchos de los trabajos que incorporan algún tipo de análisis subnacional lo hacen desde una óptica simplificadora en la que distingue solamente el interior del litoral. Esto indica que no existen investigaciones con una mirada de conjunto del país que analicen el impacto y el grado de participación de las provincias y que, a su vez, tengan en cuenta la gran heterogeneidad de las mismas.

En este sentido, las preguntas que guían este trabajo son: 1) ¿el mayor crecimiento económico ocurrido a hasta ese momento, y tantas veces descrito, impulsó el crecimiento de las provincias? 2) En parte ligado a lo anterior, ¿el crecimiento económico sirvió para homogenizar en términos económicos las diferentes regiones del país?² y, de ser así, ¿qué características tuvo en cada caso dicho crecimiento? o, por el contrario, ¿qué les impidió a ciertos territorios el 'acople' a la Belle Époque? 3) Qué singularidades y características comunes tuvieron las performances provinciales para dilucidar, entre otras cosas, si la dicotomía interior-litoral es válida para describir la época.

Desde ya que no es posible responder a estas cuestiones de manera exhaustiva, pero sí esbozar algunas ideas que permitan delinear una investigación más profunda y extensa que pueda abarcar estas cuestiones planteadas. Para esto, se aborda el problema a través de la fiscalidad, como ya se ha utilizado para analizar otros periodos de la historia como el colonial y los siglos XVIII y XIX. Muchos de estos trabajos consideraron a las arcas de los Estados como una aproximación a la evolución de la actividad económica, dada la estrecha relación entre recaudación y esta última. En este sentido, el indicador que más se ha utilizado para evaluar las performances es la recaudación per cápita.

Si bien en este trabajo se analiza esta recaudación, se lo hace desglosando sus componentes, es decir: población y recaudación total. De esta forma es posible discriminar las razones de los cambios en los niveles per cápita identificando cuándo un crecimiento es explicado por un aumento de la recaudación -lo que indicaría un crecimiento de la actividad económica- y cuándo por una baja o estancamiento de la población -lo que indicaría lo contrario-.

1 Algunos de la trabajos más destacado de esta literatura son Fogarty, Gallo, y Diéguez, 1979; Denoon, 1983; Duncan y Fogarty, 1984; Platt y Di Tella, 1985; Solberg, 1985; Bértola y Porcile, 2002; Gerchunoff y Fajgelbaum, 2006; Willebald, 2007.

2 Por otros trabajos sabemos que sí coexistieron una gran heterogeneidad de casos provinciales en cuanto a la evolución de los niveles de vida (Sánchez, 2015).

tiempo\&economía

Vol. 4 N. ${ }^{\circ} 2$ - Julio - Diciembre de 2017

p. 91 
Se incorpora, además, un examen complementario de las fuentes de financiamiento, que quizás sea el aporte más significativo de este trabajo, lo que enriquece cualitativamente los resultados obtenidos de la comparación de las evoluciones de la recaudación per cápita. Esto permite integrar un análisis de los cambios y continuidades en las estructuras económicas de cada una de las provincias. Para esto se distinguen, dentro de la recaudación, los impuestos que gravaban la riqueza y las transacciones económicas en general de aquellos que recaían en una determina actividad y, a su vez, de los recursos provenientes de la Nación en forma de subsidio. Con este análisis se agrupan las provincias por sus similitudes en cuanto a las características que hayan tenido el desempeño de dichas variables y describir de manera cuantitativa y cualitativa la diversidad de performances provinciales, superando la división simplificadora de interior y litoral.

Esta forma de aproximación a la cuestión no deja de tener restricciones, ya que al tomar la recaudación provincial como un indicador de actividad económica debemos considerar una serie de limitaciones: en primer lugar, la evolución de la recaudación se explica no solamente por los cambios en la actividad económica, sino también por las capacidades administrativas o de la burocracia de esos Estados, cuestión que es casi imposible de diferenciar en una serie temporal. En segundo lugar, no se tienen en cuenta a los municipios; si bien esto es correcto desde el punto de vista fiscal, porque son distintas arcas, no lo es desde el punto de vista económico donde las ciudades, sobre todo las capitales, fueron muy importantes en cuanto actividad económica, sobre todo en la producción de servicios. Esto último es posible subsanarlo parciamente incorporando las principales ciudades de cada provincia en un futuro trabajo, aunque por los datos ya recogidos, su incorporación no cambiaría las conclusiones generales de esta investigación.

Este trabajo se estructura de la siguiente manera: en el primer apartado se realiza un breve repaso de las investigaciones, dentro de la historiografía argentina, que utilizaron las arcas provinciales para decir algo sobre la evolución económica de un territorio particular. Luego, en la sección siguiente, se efectúa una descripción de las fuentes que se utilizaron en este trabajo para analizar el periodo 1880-1913 en particular. En la tercera parte se analizan las evoluciones de las recaudaciones per cápita provinciales a través del estudio de sus componentes - los recursos de los erarios provinciales combinados con un análisis de la población-. De manera complementaria, en el apartado que le sigue se examinan las fuentes de financiamiento de cada provincia. Por último, se resumen las distintas performances provinciales clasificándolas en grupos y se plantean algunas conclusiones.

\section{Investigaciones históricas con fuentes fiscales}

Existe una amplia producción académica en la bibliografía argentina sobre fiscalidad, tanto para el periodo colonial como para los siglos XVIII y XIX. A través de los estudios comparados se ha contribuido a ilustrar mejor el desempeño económico que tuvieron ciertas regiones del país. Algunas de estas investigaciones son clásicas dentro de la historia económica, empezando por el trabajo precursor de Miron Burgín (1960), divulgado en español en 1960 pero publicado en el año 1946, así como la obra de Tulio Halperín Donghi, de principios de los ochenta, fue continuada por los estudios de Garavaglia y Chiaramonte y, a principios de los noventa, 
por los de Samuel Amaral, Ferreyra y Romano (Halperin-Donghi, 1982; Chiaramonte, 1986; Ferreyra, 1986; Garavaglia, 1987; Amaral, 1990; Romano, 1992). Dichas publicaciones se dieron a la tarea de estudiar la fiscalidad en las postrimerías del periodo colonial y los inicios de la etapa independiente; centrándose en las finanzas de las provincias del litoral y Córdoba.

Para el último cuarto del siglo XIX, periodo que abarca esta investigación, Balán y López (1977) compararon la evolución de los recursos públicos de Tucumán y Mendoza durante la expansión del azúcar y la vitivinicultura respectivamente. Este trabajo evalúa el grado de autonomía de esas dos provincias frente al gobierno nacional y frente a los intereses de los sectores dominantes de la economía provincial. Si bien el objetivo no es el mismo, en la presente investigación se sigue en muchos casos el abordaje metodológico utilizado por estos autores.

En los últimos años resurgió una creciente producción de investigaciones con base en fuentes fiscales. Buena parte de ellos pondera la relación entre los Estados provinciales y la Nación, con especial énfasis en la formación y consolidación del sistema político nacional. Este es el caso de la tesis doctoral de Llach, que profundiza sobre los efectos que tuvieron en la política económica los intereses regionales durante el periodo que se contempla en este trabajo, y muestra las disparidades económicas entre la provincia de Buenos Aires y el resto del país a través de los recursos fiscales (Llach, 2004). En un plano análogo se encuentra el libro Desorden y progreso publicado por Gerchunoff, Rocchi y Rossi en el año 2008, en el que desde las finanzas nacionales se indaga sobre la puja distributiva que existió entre las provincias en las últimas dos décadas del siglo XIX (Gerchunoff, Rocchi, y Rossi, 2008).

Otras publicaciones analizan desde un enfoque provincial las finanzas públicas, entre las que se pueden mencionar las elaboradas para Tucumán por Bliss y por Herrera y Parolo; para Santa Fe por De los Ríos; los trabajos de Alvero para Catamarca, de Schaller para Corrientes y Fandos para Jujuy, entre otros (Rex Bliss, 2004; Alvero, 2006; De Los Ríos, 2010; Herrera y Parolo, 2012; Schaller, 2012; Fandos, 2013).

Otros trabajos han ampliado el foco del análisis a través de la comparación interprovincial de los recursos fiscales. Entre estos se ubican los trabajos de Gelman y Santilli, en los que comparan la economía de Buenos Aires con el resto del país -en especial con Córdoba- en el periodo posterior a la Independencia (Gelman, 2008; Gelman Y Santilli, 2010). En esta misma línea se ubica un libro coordinado por el propio Gelman, que recopila una serie de investigaciones de distintos autores, sobre la desigualdad en el siglo XIX (Gelman, 2011). El libro abarca gran parte del territorio argentino del siglo XIX, pues incluye estudios sobre nueve provincias -incluida la ciudad de Buenos Aires- unidos por una fuente y una metodología común que permiten hacer un ejercicio de comparación a través los registros fiscales de la contribución directa.

\section{Fuentes}

Los cortes temporales que se analizan en este trabajo son los años 1880, 1895 y 1913. La fuente de información fiscal para el año 1880 es el Informe sobre la deuda pública, bancos, acuñación de moneda y presupuestos y leyes de impuestos de la Nación y las provincias, publicado por el presidente del Crédito Público, Pedro Agote (1888). Para 1895 y 1913 se extrajo la información de los Anuarios de la Dirección General de Estadística, que continúan con la información 
brindada en la publicación de Agote. En ambas se detalla la recaudación de las arcas provinciales por tipo de impuesto. Además, a partir del año 1894 se incorporó el relevamiento de la misma información para los principales municipios del país, lo que permite contar con estos datos para la ciudad de Buenos Aires, que hasta 1880 fue parte de la provincia de Buenos Aires.

Para constatar la serie construida con base en estas fuentes, se incorporan las investigaciones sobre finanzas públicas provinciales, mencionadas más arriba, que en su gran mayoría utilizan como principal fuente las memorias anuales del gobernador, mientras que los datos de población fueron extraídos de la estimación de Francisco Latzina para 1880, publicados en los mismos Anuarios de la Dirección General de Estadística y para los dos años restantes de los censos nacionales que coinciden con dichos años de corte.

\section{Población y recaudación}

Como se mencionó en la introducción, si bien el indicador que se utiliza comúnmente para evaluar la evolución económica de un territorio es la recaudación en términos per cápita (presentado en la Tabla 3), es importante distinguir las causas de sus variaciones, es decir, si los cambios en el mismo se explican en mayor medida por las variaciones de la recaudación o de la población. Esto evita extraer conclusiones sesgadas sobre el desempeño económico, como por ejemplo cuando el crecimiento de dicho indicador fue producto más del bajo crecimiento poblacional que de un crecimiento de la recaudación, sobre todo en este periodo en el que ocurrieron grandes cambios a nivel de peso poblacional por regiones.

En primer lugar se observará la evolución de la población, que, como se aclaró anteriormente, puede ser útil para evaluar la evolución económica de cada provincia. Un crecimiento de la población es un indicador indirecto de la capacidad para mantener el crecimiento natural de su población y, en muchos casos, de la capacidad de recibir contingentes de población de otras regiones del país o del extranjero. Esto es así, sobre todo antes, del proceso de transición demográfica que en estas regiones se producirá hacia finales de la etapa bajo consideración, aunque hubo particularidades provinciales, en las cuales la evolución demográfica se independiza en cierto sentido de los recursos disponibles (Pantelides y Rofman, 1983; Somoza, 1973).

Según los datos disponibles de población (Tabla 1), se observa una clara tendencia a la concentración de la misma. Esta se aglutinó principalmente en la provincia y la ciudad de Buenos Aires y en la provincia de Santa Fe. En estas tres jurisdicciones habitaba el $40 \%$ de la población en 1880 , mientras que tres décadas después se concentraba el $60 \%$ de la misma. La diferencia se hace más evidente si se consideran las tasas anuales promedio de crecimiento de la población, que durante el periodo 1880-1914 fue del 3,5\% en promedio para el total de las provincias. Aunque por encima de este guarismo se ubicaron solamente las tres provincias anteriormente mencionadas y, una centésima más arriba, Mendoza, que fue un caso particular entre las provincias del interior (Martínez, 1916). 
Tabla 1. Porcentaje de la población por provincias y tasa anual promedio de crecimiento, 1880-1914

\begin{tabular}{|c|c|c|c|c|}
\hline Provincias & 1880 & 1895 & 1914 & $1880-1914$ \\
\hline Buenos Aires & $21 \%$ & $24 \%$ & $27 \%$ & $4,2 \%$ \\
\hline Capital Federal & $13 \%$ & $17 \%$ & $21 \%$ & $4,9 \%$ \\
\hline Catamarca & $4 \%$ & $2 \%$ & $2 \%$ & $1,0 \%$ \\
\hline Córdoba & $11 \%$ & $9 \%$ & $10 \%$ & $3,1 \%$ \\
\hline Corrientes & $7 \%$ & $6 \%$ & $5 \%$ & $2,2 \%$ \\
\hline Entre Ríos & $8 \%$ & $8 \%$ & $6 \%$ & $2.5 \%$ \\
\hline Jujuy & $2 \%$ & $1 \%$ & $1 \%$ & $1,7 \%$ \\
\hline La Rioja & $2 \%$ & $2 \%$ & $1 \%$ & $1 \%$ \\
\hline Mendoza & $3 \%$ & $3 \%$ & $4 \%$ & $3,6 \%$ \\
\hline Salta & $4 \%$ & $3 \%$ & $2 \%$ & $1 \%$ \\
\hline San Juan & $3 \%$ & $2 \%$ & $2 \%$ & $1,6 \%$ \\
\hline San Luis & $3 \%$ & $2 \%$ & $1,5 \%$ & $1,8 \%$ \\
\hline Santa Fe & $6 \%$ & $10 \%$ & $12 \%$ & $5,3 \%$ \\
\hline Santiago & $6 \%$ & $4 \%$ & $3 \%$ & $1,8 \%$ \\
\hline Tucumán & $6 \%$ & $6 \%$ & $4 \%$ & $2.5 \%$ \\
\hline
\end{tabular}

Fuente: Anuario Estadístico de la Nación, 1880; Segundo Censo Nacional, 1895; Tercer Censo Nacional, 1914.

La Tabla 2 sintetiza el peso de los recursos de cada provincia sobre la suma total de los mismos. Se observa que en todas las provincias la tasa de crecimiento de sus recaudaciones nominales fue mayor al de la población. Incluso, para tener una idea en términos reales, todas registraron una tasa promedio anual de crecimiento de las recaudaciones mayor a la de los precios al consumidor, que según la compilación realizada por Ferreres (2005) fue del 1,6\% anual ${ }^{3}$.

En paralelo se verifica, también, una gran concentración de recursos en la ciudad y la provincia de Buenos Aires, que recaudaban al final del periodo dos tercios del total de los recursos provinciales, cuando representaban menos de la mitad de la población. Si a estas dos jurisdicciones se les adiciona la provincia de Santa Fe, la concentración es aún más notoria, ya que en 1880 estas reunían el 70\% de los recursos y el 40\% de la población, y en 1913 el 75\% y $55 \%$ respectivamente. En el extremo opuesto, la suma de los recursos de Jujuy, Santiago, Salta, La Rioja y Catamarca representaban el $6 \%$, y el $18 \%$ de la población en 1880, mientras que en 1913 el 3,5\% de la recaudación y el 8\% de la población.

3 Para poder realizar correctamente esta comparación se necesitarían índices de precios al consumidor por provincias, ya que la serie de Ferreres fue construida en base a información proveniente en su mayoría de la ciudad de Buenos Aires. Si bien no se cuenta con estas series por provincias sí se sabe, con base en diferentes trabajos, que las diferencias de precios pudieron ser significativas (Balán, 1976; Correa Deza y Nicolini, 2014). 
Tabla 2. Porcentaje que representa la recaudación de cada provincia en la suma total de recaudaciones provinciales.

Tasa de crecimiento promedio anual, 1880-1913

\begin{tabular}{|c|c|c|c|c|}
\hline \multirow{2}{*}{ Provincias } & \multirow{2}{*}{$1880^{*}$} & 1895 & 1913 & \multirow{2}{*}{$1880-1913$} \\
\cline { 1 - 4 } Buenos Aires & \multirow{2}{*}{$61.6 \%$} & $30.6 \%$ & $36.0 \%$ & \multirow{2}{*}{$9.7 \%$} \\
\cline { 1 - 3 } Capital Federal & & $26.6 \%$ & $30.0 \%$ & $4.6 \%$ \\
\cline { 1 - 4 } Catamarca & $1.7 \%$ & $0.5 \%$ & $0.4 \%$ & $10.9 \%$ \\
\hline Córdoba & $4.2 \%$ & $4.3 \%$ & $6.6 \%$ & $6.0 \%$ \\
\hline Corrientes & $6.6 \%$ & $3.0 \%$ & $2.3 \%$ & $7.3 \%$ \\
\hline Entre Rios & $8.4 \%$ & $9.3 \%$ & $4.4 \%$ & $8.3 \%$ \\
\hline Jujuy & $0.4 \%$ & $0.4 \%$ & $0.3 \%$ & $7.0 \%$ \\
\hline La Rioja & $0.8 \%$ & $0.2 \%$ & $0.4 \%$ & $12.8 \%$ \\
\hline Mendoza & $1.5 \%$ & $1.8 \%$ & $4.0 \%$ & $7.2 \%$ \\
\hline Salta & $1.7 \%$ & $1.0 \%$ & $0.9 \%$ & $8.2 \%$ \\
\hline San Juan & $1.6 \%$ & $1.2 \%$ & $1.1 \%$ & $7.6 \%$ \\
\hline San Luis & $1.3 \%$ & $1.0 \%$ & $0.8 \%$ & $9.9 \%$ \\
\hline Santa Fe & $6.4 \%$ & $13.6 \%$ & $7.4 \%$ & $9.6 \%$ \\
\hline Santiago & $1.4 \%$ & $1.3 \%$ & $1.5 \%$ & $10.6 \%$ \\
\hline Tucumán & $2.4 \%$ & $5.1 \%$ & $3.4 \%$ & $9.4 \%$ \\
\hline total & $100.0 \%$ & $100 \%$ & $100 \%$ & \\
\hline
\end{tabular}

* Ciudad y provincia de Buenos Aires pertenecían a una única jurisdicción

Fuente: elaboración propia con base en Agote (1888) y Anuarios de la DGE.

Dicho esto, es posible distinguir al menos tres situaciones diferentes en cuanto a la evolución de los recursos del Estado provincial y su población, comparando las performances particulares con el promedio general. En primer lugar, aquellas provincias que tuvieron un fuerte crecimiento poblacional y de sus recursos, como fue el caso de Ciudad y Provincia de Buenos Aires, Santa Fe, Córdoba y Mendoza. En un segundo grupo se encuentran aquellas provincias que tuvieron un crecimiento cercano al promedio de sus recursos públicos, pero un bajo crecimiento poblacional, como Tucumán, Jujuy, Santiago del Estero, y San Juan. Por último, se puede identificar las que combinaron un crecimiento bajo en ambas variables, por debajo del promedio nacional en ambos aspectos, entre las que se encuentran la provincias de Catamarca, Corrientes Entre Ríos, Salta, La Rioja y San Luis. En conclusión, se identifica un incremento general de las recaudaciones per cápita, aunque con grandes diferencias en las tasas de crecimiento de sus componentes.

Otro fenómeno a destacar es la permanencia de las mismas provincias en los extremos. Durante todo el periodo, tres provincias del litoral, Capital Federal, Buenos Aires y Santa Fe, se ubicaron en el extremo superior, mientras que las provincias del norte como La Rioja, Jujuy, Santiago del Estero, Salta y Catamarca no abandonaron en ningún momento la parte baja del listado. 
Tabla 3. Recaudación per cápita, 1880, 1895 y 1913 (en pesos, moneda nacional)

\begin{tabular}{|c|c|}
\hline \multicolumn{2}{|c|}{1880} \\
\hline Provincias & $\$ m / n$ \\
\hline Buenos Aires* & 6,6 \\
\hline Entre Ríos & 4,0 \\
\hline Santa Fe & 3,6 \\
\hline Corrientes & 3,5 \\
\hline Promedio & 2,3 \\
\hline San Juan & 2,0 \\
\hline San Luis & 1,9 \\
\hline Mendoza & 1,6 \\
\hline Catamarca & 1,5 \\
\hline Salta & 1,5 \\
\hline Tucumán & 1,4 \\
\hline Córdoba & 1,4 \\
\hline La Rioja & 1,2 \\
\hline Santiago & 0,9 \\
\hline Jujuy & 0,9 \\
\hline & \\
\hline
\end{tabular}

\begin{tabular}{|c|c|}
\hline \multicolumn{2}{|c|}{1895} \\
\hline Provincias & $\$ m / n$ \\
\hline Capital Federal & 18,2 \\
\hline Santa Fe & 15,6 \\
\hline Buenos Aires & 15,1 \\
\hline Entre Ríos & 14,5 \\
\hline Tucumán & 10,7 \\
\hline Promedio & 8,0 \\
\hline Mendoza & 7,2 \\
\hline San Juan & 6,7 \\
\hline Corrientes & 5,7 \\
\hline Córdoba & 5,6 \\
\hline San Luis & 5,5 \\
\hline Jujuy & 4,0 \\
\hline Salta & 3,8 \\
\hline Santiago & 3,6 \\
\hline Catamarca & 2,5 \\
\hline La Rioja & 1,2 \\
\hline
\end{tabular}

\begin{tabular}{|c|c|}
\hline \multicolumn{2}{|c|}{1913} \\
\hline Provincias & $\$ m / n$ \\
\hline Capital Federal & 32,8 \\
\hline Buenos Aires & 30,0 \\
\hline Santa Fe & 25,2 \\
\hline Mendoza & 20,6 \\
\hline Entre Ríos & 17,6 \\
\hline Tucumán & 17,1 \\
\hline Promedio & 15,5 \\
\hline Córdoba & 15,4 \\
\hline San Juan & 14,2 \\
\hline San Luis & 11,6 \\
\hline Corrientes & 10,6 \\
\hline Salta & 10,3 \\
\hline Santiago & 9,4 \\
\hline La Rioja & 8,0 \\
\hline Jujuy & 6,7 \\
\hline Catamarca & 4,4 \\
\hline
\end{tabular}

* Corresponde a Provincia de Buenos Aires y Ciudad de Buenos Aires

Fuente: elaboración propia.

Al examinar la distancia entre el primero y el último, se observa que en 1880 y en 1913 esta fue de casi ocho veces, cuando en 1895 fue de más de quince veces. Buena parte del acercamiento en el último tramo se debió al menor crecimiento poblacional, como ya se ha mencionado, de las provincias más rezagadas que a una convergencia en términos de recaudación. Mientras que en la parte media del listado sí hubo movimientos de posiciones, en la que se encontraban tanto provincias del litoral como del interior con performances muy heterogéneas.

Entre estas últimas se destacan Mendoza y Tucumán, que fueron dos de las provincias con mayor crecimiento de sus recaudaciones. Estas son las únicas provincias del interior que lograron superar el nivel promedio de recursos per cápita durante el periodo estudiado. El crecimiento de estas economías provinciales ha sido objeto de múltiples investigaciones e incluso ha suscitado una serie de trabajos comparativos. En estos se ha ponderado que ambas provincias lograron reubicarse en el mercado interno, luego de la caída de sus principales mercados 
tradicionales de la mano de dos productos de consumo masivo, como el vino y el azúcar. También se ha destacado el rol del ferrocarril, que en 1876 llegó a Tucumán y en 1885 a Mendoza y permitió la comunicación con el creciente mercado del litoral. Además, se hizo hincapié en el rol de sus respectivas élites en la negociación con el Estado central, con el objeto de 'participar' de los beneficios del crecimiento económico impulsado por las exportaciones (Balán y López, 1977; Campi y Richard-Jorba, 2004). En ambos casos la recaudación fue motorizada en gran parte por los impuestos que gravaban las actividades productivas mencionadas, cuestión que se analiza más adelante.

No corrieron en la misma dirección las provincias de Entre Ríos y Corrientes, que geográficamente pertenece al litoral. El desempeño de la primera es llamativo por el descenso desde una posición alta a un nivel medio. Roy Hora (2010) señala este fenómeno de caída económica y lo adjudica a una menor dotación de recursos naturales y al ascenso de Santa Fe como centro comercial de la región. En consonancia, tanto el trabajo de Djenderedjian y Schmit como el que Schmit publicó de manera individual identifican una baja performance económica ya en una etapa previa a la que se está analizando aquí. Estos autores señalan que la dotación de recursos naturales fue menos apropiada para el desarrollo de explotaciones agrícolas y ganaderas más intensivas, como los granos y los ovinos, que pasaron a ser lo nuevos motores económicos. También destacan que la ocupación de la tierra se efectuó de forma más rápida que en el resto de la región pampeana, lo que consolidó la concentración de la propiedad en las mejores tierras y dejó lugar a la ocupación de los territorios menos fértiles. A esto se sumaron factores de tipo institucional que profundizaron dicha inequidad en la distribución de las tierras (Djenderedjian y Schmit, 2008; Schmit, 2008). Mientras que Corrientes, que parece no haber alcanzado previamente los niveles de riqueza de Entre Ríos, descendió por debajo del promedio, junto a las provincias pobres del noroeste, lo que la colocó como la provincia que más posiciones perdió en términos relativos.

El caso de la provincia de Córdoba parece ser la contracara de las dos anteriores. Esta provincia, que se ubica entre el litoral y el interior del país, logró recuperarse partiendo desde una posición muy baja. Lo que parece haber sido consecuencia de una de las peores crisis que hubo luego de la independencia en las economías del interior (Gelman y Santilli, 2010). En términos de recaudación, Córdoba fue la segunda provincia que más creció durante los años aquí analizados, por detrás de Mendoza.

Al no contar con una salida directa al puerto, la estrategia seguida por Córdoba fue lo que Hora (2010) Ilamó la 'pampeanización' de su economía. O dicho de manera más precisa, se produjo una 'santafenización' -si es que posible el uso de dicho termino-, tal como se describe detalladamente en la obra de Djenderedjian, Bearzotti, y Martiren (2010). Estos autores detallan cómo la expansión de la producción de trigo al sur de la provincia le permitió a esta insertase en los mercados nacionales primero y transatlánticos después. Lo interesante de este caso es que este 'acople' al crecimiento santafecino permitió no solo un crecimiento del agro, sino que también impulsó a otros sectores económicos.

Por su parte, el desempeño de la provincia de Santa Fe se vio sobre todo entre los años 1880 y 1895 , cuando la recaudación creció a una tasa del 17,4\% anual promedio, que la colocó como la segunda jurisdicción en términos de recaudación per cápita por encima de la provincia de Buenos Aires. En este mismo periodo fue también la provincia con mayor crecimiento 
poblacional. Esta etapa de la provincia fue analizada por Ezequiel Gallo (1984) en su clásico libro La pampa gringa, donde describe cómo, al compás de la expansión de la frontera y el crecimiento de las colonias agrícolas, Santa Fe se convirtió en la principal región exportadora de trigo. En otros trabajos también se describe este "boom cerealero" que bien puede plasmarse en cifras: el área sembrada con trigo se duplicó cada tres o cuatro años entre 1872 y 1892. Eso significa que en 1895 representaba el 50,2\% del área sembrada con trigo de la Argentina (Djenderedjian et al., 2010; Martiren, 2016). En definitiva, entre 1880 y 1895, Santa Fe se convirtió en el "granero del mundo", expresión muchas veces utilizada para referirse a la totalidad del país.

Por último, las dos restantes provincias cuyanas, San Juan y San Luis, tuvieron una evolución similar y relativamente estable, ubicándose apenas por debajo del promedio de recaudación por habitante durante el periodo en cuestión. Sí se observa en cambio, al final del periodo, un mayor crecimiento de la recaudación en San Juan relacionado con la producción de vino, cuestión que se aborda en el próximo apartado. También ambas provincias experimentaron un bajo crecimiento poblacional, explicado casi en su totalidad por la baja recepción de inmigrantes ultramarinos.

\section{Análisis de las fuentes de ingresos}

En este apartado se analizan las fuentes de ingresos de los erarios provinciales que permiten complementar e incorporar un elemento cualitativo a lo analizado anteriormente. Para esto se ha clasificado la recaudación en tres tipos de fuentes: 1) si procedían de alguno de los tres impuestos que constituyeron la base del sistema fiscal del periodo: las patentes, el papel sellado y la contribución directa. 2) Se distinguen a los ingresos que provenían de subsidios nacionales. 3) Se identifica la recaudación que tenía como base imponible algún sector productivo en particular, en cualquiera de sus etapas (producción, distribución o consumo).

Las patentes, papel sellado y contribución directa

Dentro de la clasificación mencionada, conviene profundizar en qué consistió cada uno de estos tres impuestos que fueron la base de la reforma fiscal posterior a 1853. En dicho año fueron suprimidas las aduanas interiores, que habían sido hasta entonces la fuente de recursos más importante para las provincias. A partir de 1854 la Nación, por medio de una ley, compensó a las provincias por estos recursos perdidos (Gaggero y Grasso, 2005; Santilli, 2010).

El impuesto a las patentes era un impuesto que alcanzaba diversos ramos, generalizado en las provincias argentinas, que pesaba sobre los beneficios de las industrias, profesiones, oficios, artes y comercio. Si bien era una continuación de las licencias coloniales, se estableció con las reformas de la década de 1820 y fue cambiando y adaptándose a nuevas situaciones de las economías provinciales (Balán y López, 1977). Este impuesto es un indicador de la evolución de varias actividades económicas pero, por sobre todo, del comercio, pues era, por sus características, sobre el que mayormente recaía dicho impuesto (Agote, 1888).

El papel sellado, por su parte, servía a diversas actividades financieras (letras, órdenes de pago, pagares), a la compra y venta de bienes raíces, a escritos judiciales de todo tipo, protocolos, partidas y diplomas. Se estructuraba en escalas que variaban de provincia en provincia, 
donde se le asignaba un precio al sellado según el valor de las obligaciones. La recaudación de este impuesto seguía el ritmo de la población y de las operaciones civiles y financieras (Agote, 1888; Balán y López, 1977).

Por último, la contribución directa fue un impuesto a la riqueza, sobre todo inmueble y en menor medida mobiliaria (ganado y cereales) -aunque en algunas provincias también se incluían capitales en giro- que en muchos casos se superponía con las patentes (Balán y López, 1977; Gelman y Santilli, 2006).

En el siguiente gráfico se presenta la evolución de la proporción que representó lo recaudado por estos tres impuestos en la suma total de ingresos de las provincias. En este se ve un claro crecimiento de la importancia de la contribución directa que representaba algo más del 15\% de la recaudación en 1880 y casi un cuarto de la misma en 1913, en detrimento del papel sellado que tuvo la evolución inversa. Las patentes parecen haber tenido una evolución más estable y representaron en promedio un poco más del $10 \%$ de la recaudación total en el periodo.

Gráfico 1. Porcentaje de los principales ingresos en el total de recursos provinciales, 1880, 1895 y 1913

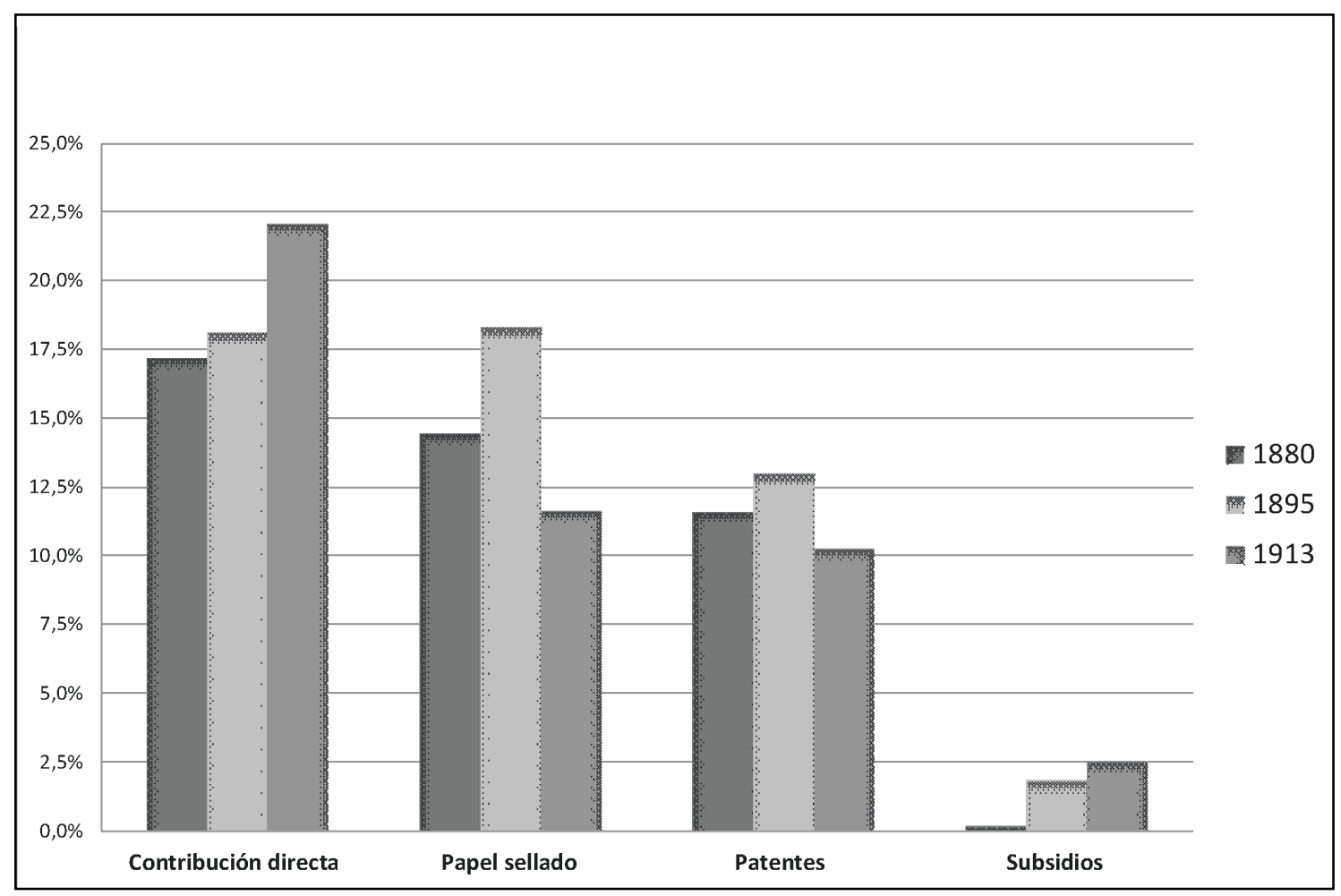

Fuente: elaboración propia con base en Agote (1888) y en los Anuarios de la Dirección General de Estadística.

Sin embargo, fue muy disímil el peso en la recaudación de estos tres impuestos en cada provincia, tal como se puede apreciar en el Gráfico 2. Dentro de esta diversidad de situaciones se observan solo tres provincias que durante todo el periodo tuvieron una proporción de la recaudación proveniente de estos tres tributos por encima del promedio: la provincia de Buenos Aires, Córdoba y Santa Fe. 
Gráfico 2. Porcentaje de la recaudación proveniente de la suma de Contribución Directa, Patentes y Sellado

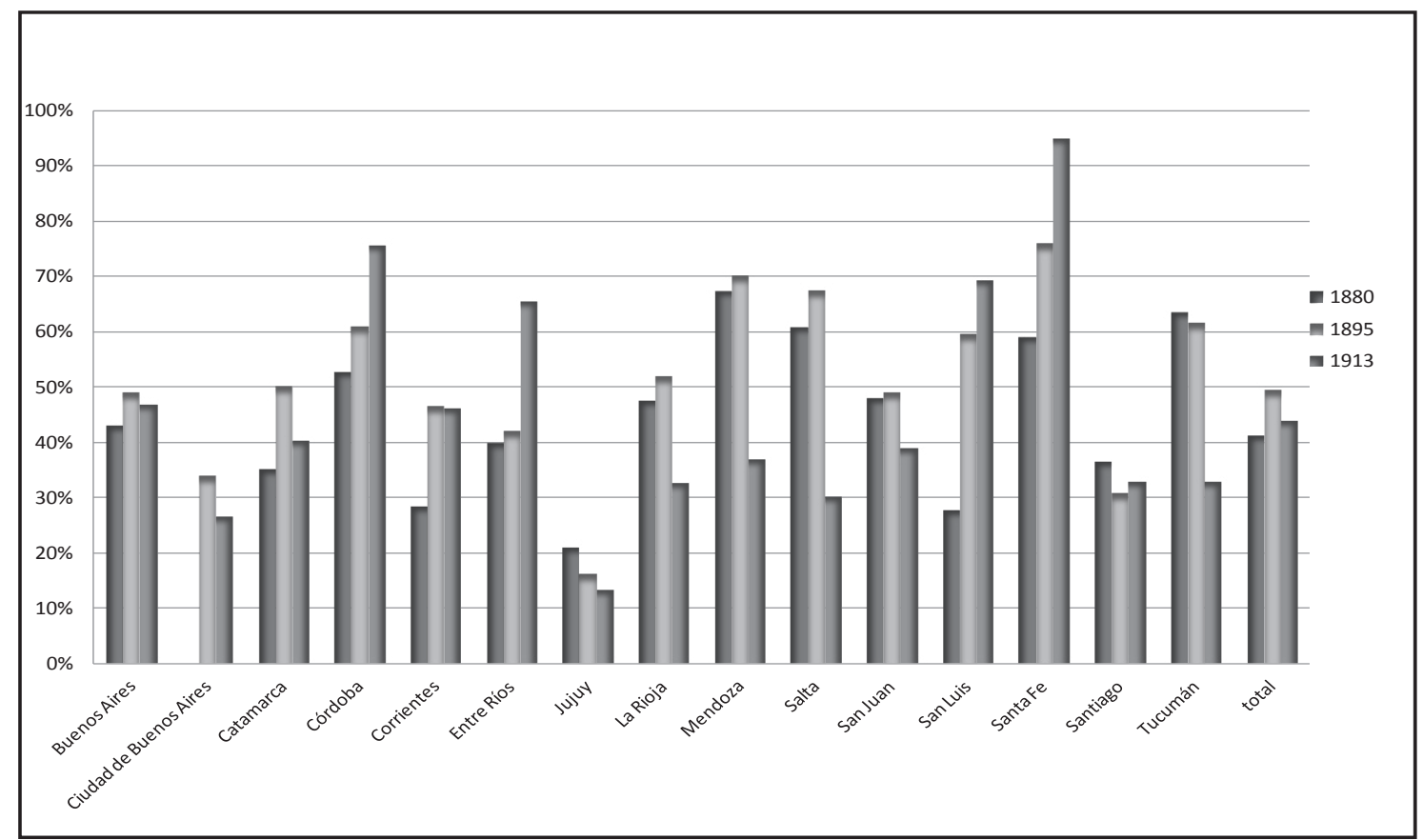

Fuente: elaboración propia con base en Agote (1888) y en los Anuarios de la Dirección General de Estadística.

En el caso de la provincia de Buenos Aires, debe tenerse en cuenta que la década del ochenta fue conflictiva para el erario, ya que tras la federalización de la ciudad "la provincia pierde de modo definitivo las rentas de la Aduana y lo recaudado por Contribución Directa en la urbe" (Gaggero y Grasso, 2005, p. 19). Esto implicó que las recaudaciones provenientes de la contribución directa y de las patentes cayeran a más de la mitad de un año para otro y que no volvieran a los niveles nominales previos a 1880 durante ninguno de los años aquí analizados. Mientras que la recaudación en concepto de papel sellado creció en términos absolutos y relativos dentro del arca provincial, que pasó a representar más del cuarto de los ingresos en 1895. Este último impuesto permitió sortear de mejor manera la pérdida de recursos provenientes de la contribución directa, que recién a principios del siglo XX volvió a ser la principal fuente de recaudación ${ }^{4}$.

El desempeño de Santa Fe se destacó por la creciente proporción de ingresos provenientes de estos tres impuestos, que representaron casi la totalidad de su recaudación (95\%) al finalizar el periodo. Esta evolución no fue uniforme en cuanto a la composición de cada uno de los impuestos: durante los primeros años de la década del 80, las patentes fueron el impuesto más importante y el que más creció. Más tarde, el papel sellado y la contribución directa fueron alternándose como la principal fuente de ingreso. Tampoco fue este el producto de un desarrollo pacífico, sino que fue acompañado y moldeado por muchos conflictos. Algunos de ellos están muy bien descritos por Ezequiel Gallo (1984) y aludidos en los trabajos de Balán y

4 En algunos años la Nación compensó parcialmente está perdida, con envíos en concepto de "Cesión del municipio de Buenos Aires" o con alguna clase de subsidio a la educación. 
López (1977) y de Djenderedjian et al. (2010), señalando las reacciones sociales que surgieron ante las estrategias de los Estados provinciales para capturar mayores ingresos luego de la crisis de 1890.

Córdoba tuvo una evolución similar, pero a un nivel inferior, a la de Santa Fe: a finales del periodo tres cuartas partes de sus ingresos provenían de la recaudación de estos tres impuestos. El monto generado por las patentes tuvo un gran crecimiento, que representaba alrededor del $20 \%$ de los ingresos al inicio y un tercio de los mismos durante toda la última década aquí analizada. Gran parte del incremento de este impuesto se debió a la expansión del comercio cordobés, tal como lo analiza en profundidad el trabajo de Converso (2001). Este autor describe el considerable crecimiento de esta actividad a fines del siglo XIX, sobre todo a partir de 1895, al calor de la expansión agrícola del sur de la provincia.

La ciudad de Buenos Aires debe ser analizada de manera especial, ya que luego de su federalización, su estatus fiscal fue diferente al de un municipio, pero tampoco se igualó al de una provincia ${ }^{5}$. Esto implicó que no recaudara en concepto de papel sellado ni de contribución directa. El primero ya venía siendo cobrado anteriormente por la Nación para el uso de las administraciones, oficinas y tribunales nacionales. La contribución directa correspondiente a la ciudad también fue recaudada por el Estado central a partir de 1881 (Agote, 1888). El impuesto a las patentes sí fue parte de los ingresos del erario capitalino y representó alrededor del $10 \%$ de los mismos durante este periodo.

En este caso fue el Impuesto General, un impuesto municipal que gravaba el valor inmueble, el impuesto directo más importante para el arca ${ }^{6}$. La recaudación en concepto del mismo constituyó un cuarto de los ingresos en 1895 y el 20\% en 1913, debido al crecimiento de impuestos indirectos como Construcción y catastro e Hipódromos y, en particular, de los recursos derivados del dominio público. Este último gravaba la ubicación de los avisos en la vía pública, en el interior y exterior de los coches de tranvías, estaciones de ferrocarriles, líneas y postes, y por la colocación de mesas y sillas al frente de los negocios. Según la evolución de la recaudación por este concepto, puede señalarse que estas actividades relacionadas a la producción de servicios tuvieron un gran crecimiento desde 1903, año en el que se estableció dicha renta en la ciudad capital.

En las provincias Entre Ríos y Corrientes los tres impuestos analizados en este apartado crecieron en importancia relativa dentro de sus ingresos, pero como causa del descenso de otras fuentes más que por el aumento de dichos impuestos. En la primera de estas provincias la recaudación que provenía de gravar a los saladeros cayó precipitadamente a partir de mediados de la década del 80, cuando durante la primera mitad de esa década llegó a representar un tercio de la recaudación. A partir de la serie construida se constata que esta actividad tuvo un corto apogeo que duró una década a partir de fines de 1870. Luego esta se vio sobrepasada por los frigoríficos, que comenzaron a tener impulso a partir de la segunda mitad de 1880, ubicados mayormente en Buenos Aires (Giberti, 1981). Mientras que en Corrientes la venta de tierras fiscales, que representaba hasta 1886 más de un cuarto de las entradas a las arcas de la

5 Esta situación de la ciudad de Buenos Aires fue tema de debate en el Congreso durante el año 1882. Para más información véase, Aresti, 1936.

6 Dadas las características de este impuesto, se lo seleccionó para los cálculos expuestos en el Gráfico 2 en reemplazo de la contribución directa. 
provincia, comenzó a perder importancia. Este fenómeno también es destacado por Schaller (2012), quien interpreta esto como un intento por parte del Estado provincial, a partir de la crisis de 1890, de diversificación de las fuentes de recursos. La estrategia seguida por el Estado correntino fue la de aumentar los impuestos que gravaban a las propiedades y en menor medida a la actividad económica.

\section{Subsidios}

Los subsidios también formaron parte de los mecanismos de compensación de la Nación hacia las provincias, que fueron discutidos y legislados en la Constitución del año 1853 (Ravignani, 1939). Si bien estos crecieron en términos relativos durante estos años, nunca alcanzaron a representar más del 2,5\% dentro de la suma total de los recursos provinciales (Gráfico 1), similar al peso de las erogaciones de la Nación en concepto de pensiones y jubilaciones.

Gran parte de estos subsidios estaban destinados al fomento de la educación y en algunos casos a la prosecución de alguna obra en particular. El envío de estos fondos estuvo dirigido principalmente a seis provincias que recibían aproximadamente dos terceras partes de los mismos. Cinco de las seis provincias en cuestión eran de la región norte: Jujuy, Santiago del Estero, Catamarca, Salta y La Rioja, y San Luis, de la región de Cuyo.

El peso relativo que adquirió el subsidio nacional con respecto a los ingresos propios tuvo diferentes trayectorias por provincias. En las arcas de San Luis y Santiago del Estero la importancia fue notoriamente decreciente, tanto que al final del periodo solo representó un $5 \%$ de sus ingresos. Mientras que para los erarios de Jujuy, Catamarca y La Rioja si bien fue a la baja, las transferencias de la Nación significaron una porción importante de la recaudación, en torno al 20\%. En el caso de Salta, los subsidios crecieron en importancia en los últimos años, al igual que los ingresos en concepto de venta de tierras fiscales. Entre los años 1911 y 1913 el ingreso por venta de tierras fiscales llegó a representar entre un $28 \%$ y $36 \%$, cuando en los años anteriores no superaba el 3\%. Esto explica, en gran parte, el crecimiento de sus ingresos durante los últimos años aquí analizados (Justiniano y Tejerina, 2005).

En el siguiente gráfico se ofrece una aproximación alternativa de la importancia que tuvo para estas provincias las transferencias recibidas desde la Nación. En este se observa la proporción de la plantilla existente en cada año que se podía pagar con dicha contribución. Si bien para la mayoría de las provincias fue perdiendo importancia relativa, este ingreso no llego a ser insignificante para ninguna de las arcas aquí analizadas. En especial para las provincias de Jujuy y Catamarca en las que representaba prácticamente la mitad de los egresos en concepto de salario. 
Gráfico 3. Proporción de los empleados a los que equivalía el monto del subsidio nacional

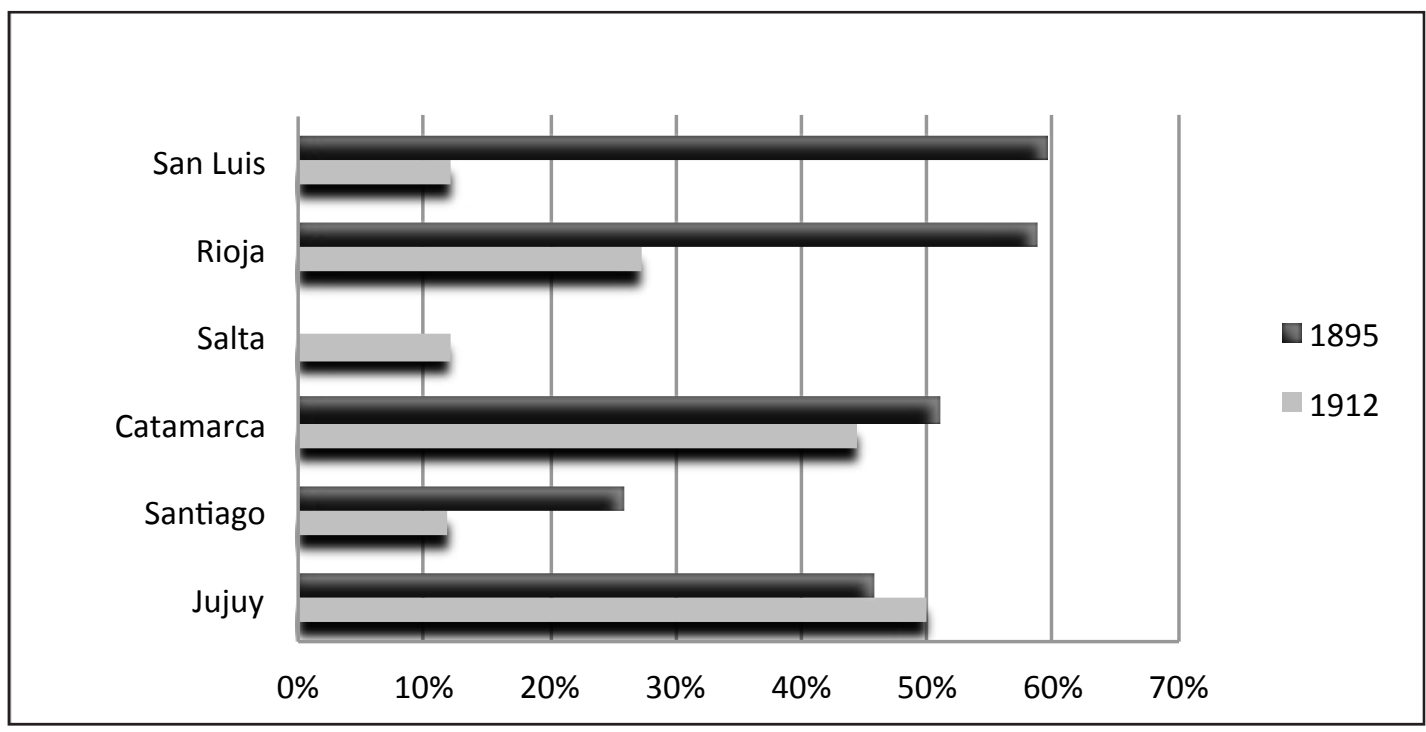

Fuente: elaboración propia con base en los Anuarios de la Dirección General de Estadística, tanto para los datos fiscales como salariales.

\section{Impuestos a un sector productivo específico ${ }^{7}$}

Este tipo de ingreso fue muy importante para las arcas de un conjunto de provincias del interior. Según algunas investigaciones, debe rastrearse la razón principal de ello en la crisis de 1890, cuyo impacto sobre las cajas obligó a los Estados provinciales a buscar nuevas fuentes de ingresos, viendo en los sectores económicos en crecimiento una solución posible a sus problemas financieros (Balán y López, 1977; Caravaca, 2009; Román, 2013). Si bien la importancia de estas industrias seguramente no podía pasar desapercibida para las autoridades gubernamentales, también debe tenerse en cuenta que representaron una fuente de ingresos más accesible -y menos conflictiva- que gravar la riqueza.

En este sentido, podría asemejarse a lo que sucedía a nivel nacional con el impuesto a las importaciones, que resultaba más simple de recaudar para la "joven burocracia", que un impuesto a las ganancias (Rocchi, 2005). A esto debe sumarse un elemento presente en varias investigaciones sobre la época: la existencia de una suerte de negociación implícita entre las élites y el Estado nacional. Con las industrias del interior, la negociación implicaba la protección de estas por parte de la Nación a cambio de, entre otras cosas, que estas demandas en empleo (Alonso, 2010; Gerchunoff et al., 2008; Hora, 2002).

Tal como puede apreciarse en el siguiente gráfico, en el que se agregó un año de referencia más para poder apreciar de mejor manera la evolución, el peso que tuvo este tipo

7 En este análisis se tienen en cuenta solamente los impuestos provinciales, ya que también podían recaer impuestos nacionales, sean internos o a la exportación, sobre estos mismos sectores. 
de ingresos fue creciente durante este lapso, llegando a niveles cercanos al $50 \%$ en alguna de las provincias ${ }^{8}$.

Gráfico 4. Porcentaje de la recaudación proveniente de los impuestos a un sector específico

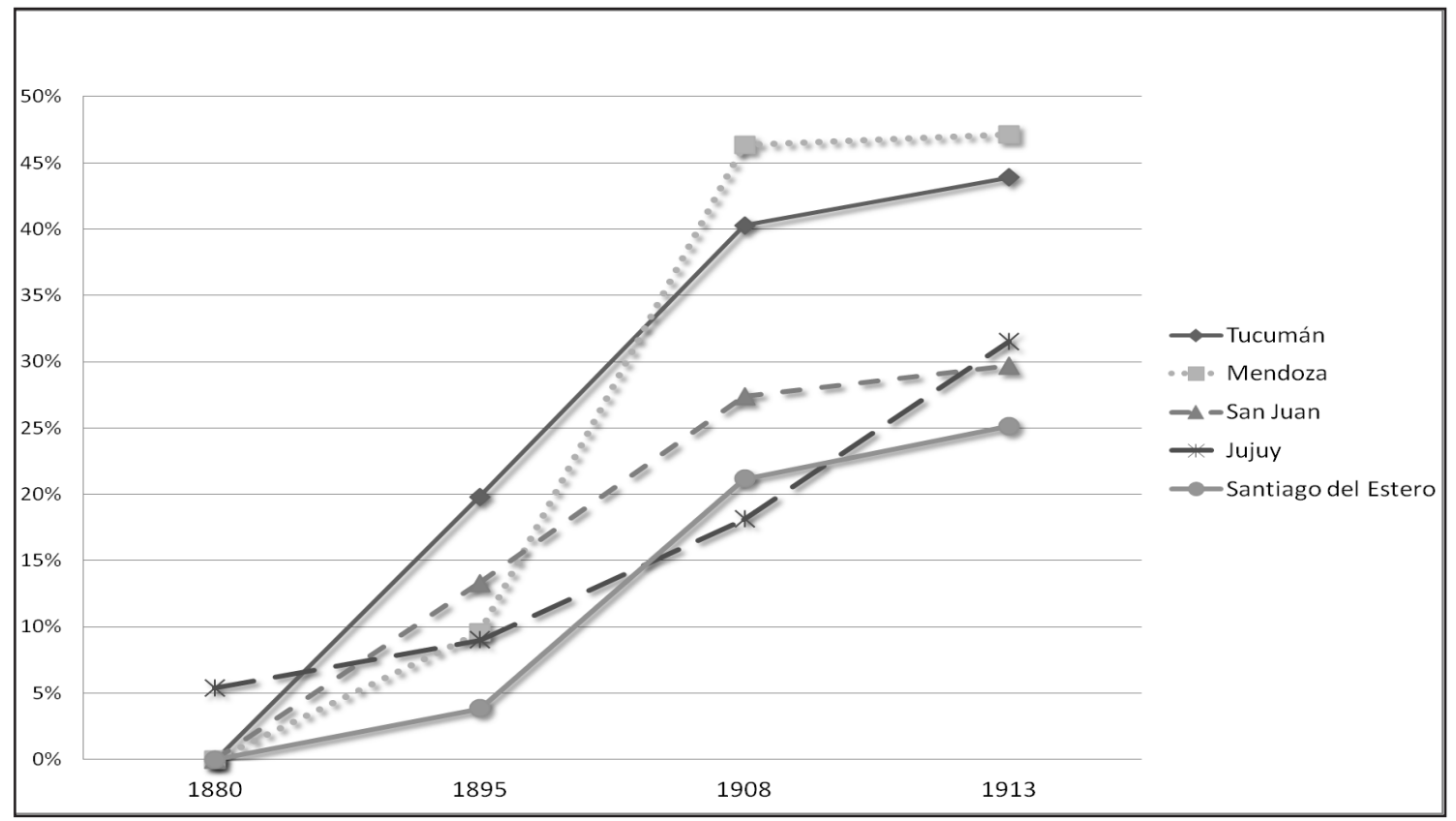

Fuente: elaboración propia con base en los Anuarios de la Dirección General de Estadística.

Como ya se ha mencionado, Tucumán y Mendoza son las dos provincias del interior que más se han estudiado en este periodo por el crecimiento de la industria del azúcar y el vino, respectivamente. El análisis que aquí se expone permite complementar la visión de estos estudios desde una aproximación cuantitativa. En el caso de Tucumán, la suma del Impuesto al Azúcar y las Patentes a la Caña de Azúcar aportaban a fines del siglo XIX lo mismo que lo que provenía en concepto de contribución directa, mientras que al final del periodo representaba el triple. El crecimiento del peso de estos impuestos en Mendoza fue más tardío que en el caso tucumano, aunque progresó más rápidamente. El presupuesto provincial de Mendoza comenzó a depender en mayor medida recién a partir de 1904 de las Patentes a las Bodegas y del Impuesto al Vino que de la contribución directa, en una relación que llegó a ser de seis a uno en algunos años.

La magnitud de estas cifras permite corroborar lo esbozado por Sánchez Román (2005) para el caso de Tucumán y por Richard-Jorba (2008) para el de Mendoza. Ambos autores describen cómo estas nuevas agroindustrias sobrepasaron en dinamismo a sectores tradicionales como el comercio tucumano y la ganadería mendocina. Esto, a su vez, provocó una nueva

8 Se optó por incluir el año 1908 ya que para dicho año se dispone del Censo Industrial y Comercial, que permite tener una comparación con los niveles de producción de cada actividad. 
relación de conveniencia entre el fisco, jaqueado por la caída de las actividades tradicionales y las industrias nacientes. En el caso de Tucumán:

La crisis de las actividades tradicionales y la caída en la recaudación fiscal procedente del comercio llevaron al gobierno provincial a estimular la industria del dulce como fuente alternativa de recaudación. (Sánchez Román, 2005, p. 151).

Por su parte, Richard- Jorba (2008) incorpora un elemento más a tener en cuenta: el hecho de que para el gobierno provincial tener una fuente de ingreso propia le otorgaba un mayor margen de acción frente al gobierno nacional. Esto puede confirmarse analizando el presupuesto de la provincia de Mendoza que no tiene entre sus fuentes de ingresos subsidios nacionales y en el caso de Tucumán, solo en algunos años y en una proporción muy baja.

Distinta fue la situación de las tres provincias restantes, que han sido menos estudiadas, en las que este tipo de fuente si bien fue en ascenso, no llegó a las proporciones que lo hizo en las dos anteriores. En el caso de Jujuy, la recaudación por los impuestos al azúcar fue del 13\% en 1895 y de un tercio de la misma al final del periodo, cifra que significaría la mitad de los ingresos si solamente se tuviesen en cuenta los recursos propios, es decir, netos de subsidio nacional $^{9}$, mientras que la industria del vino aportaba al tesoro sanjuanino en 1895 casi un 15\% del total, porcentaje que se multiplicó por dos hacia 1913.

De manera similar, la recaudación por concepto de explotación de bosques al inicio del periodo analizado equivalía a poco menos del $4 \%$ de los recursos públicos de la provincia de Santiago del Estero, para luego ser más de la cuarta parte del mismo en el año 1913. La industria del aserradero se desplegó al calor de la construcción del ferrocarril, del tendido de postes y la construcción, que crecieron exponencialmente durante el periodo ${ }^{10}$.

Aunque fue importante para el erario santiagueño, los trabajos existentes sobre este sector afirman que no produjo efectos de encadenamiento hacia el resto de la economía. Incluso algunos de estos han usado a la industria forestal como un claro ejemplo de "economía de enclave" (Bitlloch y Sormani, 2012; Dargoltz, 2003) ${ }^{11}$. Los resultados aquí encontrados corroboran esta idea al encontrar un alto crecimiento de recursos combinado con una de las mayores pérdidas de peso poblacional.

9 Debe tenerse en cuenta que el mayor crecimiento del sector azucarero en la provincia de Jujuy fue posterior al que estamos analizando en este trabajo. Para más detalles ver: Fandos, 2013.

10 La extensión del ferrocarril creció a una tasa anual promedio del 5\% en el periodo 1895-1913 (Tercer Censo Nacional, 1914). Por su parte, Irigoin destaca el tendido de las comunicaciones, entre ellos el del teléfono, que insumía una cantidad importante de postes. “En 1914 había 75.000 teléfonos instalados en el país que representaban, excluyendo a los Estados Unidos, el 32\% del total de toda América"(Irigoin, 1984).

11 Según Dargoltz las economías de enclave tienen dos características diferenciales: "en primer lugar, se trataba de núcleos de actividad económica controlados de una manera directa desde afuera del país"; en segundo lugar, estas actividades "tenían pocas vinculaciones con los eslabonamientos regionales, ya que las máquinas de sus ingenios, los ferrocarriles, los puertos, etc., provenían del exterior" (Dargoltz, 2003). 


\section{Conclusiones}

En la siguiente tabla se presenta un resumen esquematizado de la evolución de las variables que se analizaron: la población, la recaudación y la composición de las fuentes de la segunda. Además, muestra la existencia de desempeños territoriales muy variados, pero a la vez permite clasificar y describir las performances económicas de cada una de las provincias y extraer algunas conclusiones generales a la luz de las preguntas planteadas en la introducción.

Tabla 4. Resumen de las performances económicas provinciales

\begin{tabular}{|c|c|c|c|c|}
\hline $\begin{array}{l}\text { Reacaudación } \\
\text { y población }\end{array}$ & $\begin{array}{l}\text { Composi- } \\
\text { ción de la } \\
\text { recaudación }\end{array}$ & $\begin{array}{c}\text { Tres } \\
\text { impuestos tradicionales }\end{array}$ & $\begin{array}{l}\text { Impuestos a un } \\
\text { sector específico }\end{array}$ & Subsidios nacionales \\
\hline \multicolumn{2}{|c|}{$\begin{array}{l}\text { Alto crecimiento poblacional y } \\
\text { alto crecimiento de sus recursos }\end{array}$} & $\begin{array}{c}\text { Santa Fe, Córdoba, Buenos } \\
\text { Aires (provincia), Mendoza } \\
\text { (1880). }\end{array}$ & Mendoza $(1895,1913)$ & \\
\hline \multicolumn{2}{|c|}{$\begin{array}{l}\text { Bajo crecimiento poblacional y } \\
\text { alto crecimiento de sus recursos }\end{array}$} & $\begin{array}{c}\text { San Juan (1880), Tucu- } \\
\text { mán (1880, 1895), San Luis } \\
\text { (1913) }\end{array}$ & $\begin{array}{l}\text { Tucumán }(1895,1913), \text { Ju- } \\
\text { juy, Santiago del Estero, } \\
\text { San Juan }(1895,1913)\end{array}$ & $\begin{array}{l}\text { Jujuy, San Luis } \\
(1880,1895)\end{array}$ \\
\hline \multicolumn{2}{|c|}{$\begin{array}{l}\text { Bajo crecimiento poblacional y } \\
\text { bajo crecimiento de sus recursos }\end{array}$} & $\begin{array}{c}\text { Entre Ríos }(1895,1913) \\
\text { Salta }(1880,1895), \text { La Rioja } \\
(1895,1913) .\end{array}$ & $\begin{array}{c}\text { Corrientes, Entre Ríos } \\
(1880)\end{array}$ & $\begin{array}{c}\text { Catamarca, Salta (1913), La } \\
\text { Rioja }(1880,1895)\end{array}$ \\
\hline
\end{tabular}

Fuente: elaboración propia.

En primer lugar, el análisis de la evolución de la recaudación per cápita muestra que fue un periodo tanto de crecimiento económico generalizado, como de concentración de recursos y de población. Además, demuestra que no hubo movilidad en las provincias de los extremos, es decir, que las provincias con mayores y menores recursos fueron exactamente las mismas durante el periodo analizado, exceptuando la provincia Entre Ríos, que perdió posiciones.

Las jurisdicciones de mayores recursos -la ciudad de Buenos Aires, la provincia de Buenos Aires y Santa Fe- experimentaron un gran crecimiento de población y de recaudaciones. Estas últimas crecieron en base a impuestos que gravaban la riqueza, las transacciones económicas en general y los servicios, especialmente en el distrito capital. Mientras que las provincias que se mantuvieron en lo más bajo tuvieron un pobre crecimiento poblacional, lo que habla de menores oportunidades económicas, o un crecimiento de sus recursos muy por debajo de las provincias de mayor crecimiento. Incluso, el crecimiento de sus recursos se debió en gran parte a los subsidios o a los impuestos con base a una sola actividad económica. En este sentido, La Rioja, Salta y Catamarca dependieron en gran medida de los envíos de la Nación, mientras que Jujuy dependió de estos y de los impuestos sobre la naciente actividad azucarera. Por su parte, Santiago del Estero fue paradigmático como caso de dependencia de una sola actividad económica, que no implicó mejoras en la economía en general. 
Las provincias de San Luis y San Juan, si bien no pueden ser ubicadas en este último grupo ya que tuvieron un desempeño a penas por debajo del promedio, estuvieron lejos de un crecimiento que les permitiese converger con las provincias de mayores recursos. Cabe destacar que en la última década analizada se observó un fuerte crecimiento de los recursos en el caso de San Juan, sostenido por la actividad vitivinícola. Mientras que en la recaudación de San Luis cayó de manera importante la dependencia por los subsidios nacionales, en paralelo al crecimiento de los ingresos por contribución directa, papel sellado y patentes.

Distintos fueron los casos de Mendoza y Tucumán, que estuvieron entre las provincias de mayor crecimiento de sus recursos, y de su población en el caso de la provincia cuyana. Ahora bien, al analizar las fuentes de ingreso de sus arcas se verifica que este estuvo sustentado en una sola actividad productiva. Esto implicó una situación ambigua, que por un lado les permitió a dos territorios alejados del puerto articularse con lo que allí sucedía, pero por el otro implicó un 'legado' de exposición de sus economías y, por transmisión inmediata, de las arcas provinciales.

En cambio Córdoba, que fue la provincia que más posiciones escaló, se 'acopló' al puerto no solo en términos de crecimiento, sino también en cuanto a una mayor diversificación productiva, como lo reflejan sus fuentes de recaudación. Esto a su vez le permitió recuperarse de los efectos de la crisis post independencia y sortear de mejor manera las coyunturas de la economía.

Las evoluciones de las dos provincias restantes son importantes a la hora de pensar, entre otras cosas, la valides de las entidades interior y litoral para describir este periodo. Por un lado, la posición relativa de Corrientes fue en franco descenso. En 1880 se ubicaba por encima del promedio con el resto de las provincias del litoral, mientras que tres décadas después acompañaba en el fondo a las provincias del norte. Por el otro, el caso entrerriano también combinó un bajo crecimiento poblacional y de recursos fiscales en comparación con el resto de las provincias, lo cual implico la pérdida de posiciones relativas, siendo alcanzada por Tucumán y Mendoza. Los cambios percibidos en la composición de las fuentes de recaudación reflejan las dificultades que atravesó Entre Ríos al no poder ni diversificar su estructura económica ni encontrar una actividad en particular para incorporarse al crecimiento estimulado por las exportaciones.

Estas dos performances no solo permiten reflexionar sobre lo poco que explica la división del país entre litoral e interior, sino también sobre las condiciones que debe tener o crear un territorio para incrementar su producción. Sobre esto último invita a pensar que la ubicación geográfica y la ampliación de los mercados de por sí no son condiciones suficientes para el crecimiento económico, tema para abordar en investigaciones futuras. 


\section{Referencias}

Agote, P. (1888). Informe del presidente del Crédito Público Pedro Agote sobre la deuda pública, bancos, acuñación de moneda y presupuestos y leyes de impuestos de la Nación y provincias. Buenos Aires: Litografía, Imprenta y Encuadernación de Guillermo Kraft.

Alonso, P. (2010). Jardines secretos, legitimaciones públicas: El Partido Autonomista Nacional y la política argentina de fines del siglo XIX. Buenos Aires: Edhasa.

Alvero, L. A. (2006). Fiscalidad y poder político en el Noroeste Argentino. El papel de los Recaudadores de Rentas en Catamarca 1890-1910. Ponencia presentada en VI Jornadas Nacionales Espacio, Memoria e Identidad, Universidad Nacional de Rosario.

Amaral, S. (1990). Comercio y Crédito en Buenos Aires 1822-1836. Siglo XIX, 5(9), 132-157.

Aresti, I. (1936). Ensayo sobre recursos municipales: referidos especialmente a la ciudad de Buenos Aires. Buenos Aires: Talleres gráficos Casa Jacobo Peuser, Ltda.

Balán, J. (1976). Migraciones, mano de obra y formación de un proletariado rural en Tucumán, Argentina, 1870-1914. Demografía y economía, 10(2), 201-234.

Balán, J., y López, N. (1977). Burguesías y gobiernos provinciales en la Argentina: La política impositiva de Tucumán y Mendoza entre 1873 y 1914. Desarrollo Económico, 17(67), 391-435.

Bértola, L., y Porcile, G. (2002). Rich and impoverished cousins: economic performance and income distribution in Southern settler societies. Ponencia presentada en XIII International Economic History Congress. Buenos Aires.

Bitlloch, R. E., y Sormani, H. (2012). Formación de un sistema productivo: los enclaves forestales de la región chaqueño-misionera (siglos XIX-XX). Revista de Indias, 72(255), 551-580.

Burgin, M. (1960). Aspectos económicos del federalismo argentino. Buenos Aires: Hachette.

Campi, D., y Richard-Jorba, R. A. (2004). Transformaciones productivas, espaciales y sociales en la Argentina extrapampeana: Tucumán y Mendoza entre 1850 y 1890 . Boletín americanista, $54,35-62$.

Caravaca, J. (2009). Estado, economía y economistas: el caso del impuesto a la renta en la Argentina, 1890-1932. Buenos Aires: FLACSO.

Chiaramonte, J. C. (1986). Finanzas públicas de las provincias del Litoral. Anuario del IEHS, 1, 159.

Converso, F. (2001). Un mercado en expansión: Córdoba 1870-1914. Córdoba: Centro de Estudios Históricos "Profesor Carlos S. A. Segreti".

Correa Deza, M. F., y Nicolini, E. A. (2014). Diferencias regionales en el costo de vida en Argentina a comienzos del siglo XX. Investigaciones de Historia Económica (IHE) Journal of the Spanish Economic History Association, 10(3), 202-212.

Dargoltz, R. (2003). Las economías regionales argentinas y la globalización. El caso de Santiago del Estero y la explotación del quebracho colorado. Trabajo y Sociedad, 5(6).

De Los Ríos, E. (2010). Un caso de fiscalidad provincial: Santa Fe entre la Confederación Argentina y el Estado Nacional (1852-1870). Barcelona: Universidad Pompeu Fabra.

tiempo\&economía

Vol. 4 N. ${ }^{\circ} 2$ - Julio - Diciembre de 2017

p. 109

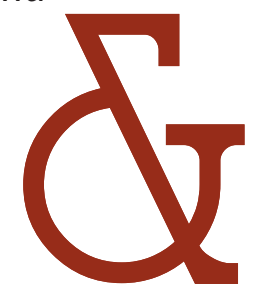


Denoon, D. (1983). Settler Capitalism: The Dynamics of Dependent Development in the Southern Hemisphere. Oxford: Clarendon Press.

Djenderedjian, J., Bearzotti, S., y Martiren, J. L. (2010). Historia del capitalismo agrario pampeano: Expansión agrícola y colonización en la segunda mitad del siglo XIX. Buenos Aires: Teseo.

Djenderedjian, J., y Schmit, R. (2008). Avances y límites de la expansión agraria argentina: crecimiento económico y distribución de la riqueza rural en Entre Ríos (1860-1892). Investigaciones de Historia Económica, 4(11), 75-106.

Duncan, T., y Fogarty, J. (1984). Australia and Argentina: on parallel paths. Melbourne: Melbourne University.

Fandos, C. A. (2013). Legislación, intereses y reformas de la contribución territorial en Jujuy, 1870-1930. Estudios Rurales, 3(4).

Ferreres, O. (2005). Dos siglos de economía argentina. Historia argentina en cifras. Buenos Aires: Fundación Norte y Sur.

Ferreyra, A. I. (1986). El erario cordobés entre los años 1835 y 1852. Investigaciones y Ensayos, $33,1835-1852$.

Fogarty, J., Gallo, E., y Diéguez, H. L. (1979). Argentina y Australia (Vol. 201). Buenos Aires: Instituto Torcuato Di Tella.

Gaggero, J., y Grasso, F. (2005). La cuestión tributaria en Argentina. La historia, los desafíos del presente y una propuesta de reforma. Documento de Trabajo, 5.

Gallo, E. (1984). La pampa gringa. Buenos Aires: Edhasa.

Garavaglia, J.C. (1987). Economía, sociedad y regiones. Buenos Aires: De La Flor S. R. L. Ediciones.

Gelman, J. (2008). La Gran Divergencia. Las economías regionales en Argentina después de la Independencia. IX Congreso de la AEHE, Murcia.

Gelman, J. (2011). El mapa de la desigualdad en la Argentina del siglo XIX. Buenos Aires: Prohistoria Ediciones.

Gelman, J., y Santilli, D. (2006). Historia del capitalismo agrario pampeano: desigualdad y crecimiento económico. De Rivadavia a Rosas. Buenos Aires: Siglo Veintiuno Editores.

Gelman, J., y Santilli, D. (2010). Crecimiento económico, divergencia regional y distribución de la riqueza: Córdoba y Buenos Aires después de la Independencia. Latin American Research Review, 45(1), 121-147.

Gerchunoff, P., y Fajgelbaum, P. (2006). ¿Por qué Argentina no fue Australia?: una hipótesis sobre un cambio de rumbo. Buenos Aires: Siglo XXI Ediciones.

Gerchunoff, P., Rocchi, F., y Rossi, G. (2008). Desorden y progreso: las crisis económicas argentinas, 1870-1905. Buenos Aires: Edhasa.

Giberti, H. (1981). Historia económica de la ganadería argentina. Buenos Aires: Ed. Solar.

Halperin-Donghi, D. (1982). Guerra y finanzas en los orígenes del Estado argentino. Buenos Aires: Editorial de Belgrano. 
Herrera, C., y Parolo, M. P. (2012). Las dos caras de la fiscalidad: Estado y contribuyentes. Tucumán, 1853-1870. Boletín del Instituto de Historia Argentina y Americana Dr. Emilio Ravignani, 34, 47-76.

Hora, R. (2002). Los terratenientes de la pampa argentina: Una historia social y política, 1860-1945 (Vol. 3). Buenos Aires: Siglo XXI Ediciones.

Hora, R. (2010). Historia económica de la Argentina: en el siglo XIX. Buenos Aires: Siglo Veintiuno Editores.

Irigoin, A. (1984). La evolución industrial en Argentina (1870-1940). Revista Libertas, 1.

Justiniano, M. F., y Tejerina, M. E. (2005). Estado, finanzas y familias: los presupuestos provinciales y su ejecución. El caso de la provincia de Salta (1880-1914). Andes, 16.

Llach, L. (2004). The Wealth of the Provinces: Buenos Aires, the Interior and the Political Economy of Argentina, 1880-1890. Cambridge, Massachusetts: Harvard University, Graduate Conference on Latin American History.

Martínez, A. B. (1916). Tercer censo nacional 1914. Buenos Aires: Talleres Gráficos de LJ Rosso.

Martiren, J. L. (2016). La transformación farmer. Colonización agrícola y crecimiento económico en la Provincia de Santa Fe durante la segunda mitad del siglo XIX. Buenos Aires: Prometeo.

Pantelides, E. A., y Rofman, A. (1983). La transición demográfica argentina: un modelo no ortodoxo. Desarrollo Económico, 22(88), 511-534.

Platt, D. C. M., y Di Tella, G. (1985). Argentina, Australia, and Canada: studies in comparative development, 1870-1965. Melbourne: Macmillan in association with St. Antony's College.

Ravignani, E. (1939). Asambleas constituyentes argentinas: 1810-1898. 2v (Vol. 6). Buenos Aires: Talleres Casa Jacobo Peuser, Ltda.

Rex Bliss, S. (2004). La fiscalidad provincial entre la constitución y el despegue azucarero. Tucumán, 1852-1876. América Latina en la Historia Económica, 11(1), 119.

Richard-Jorba, R. A. (2008). Crisis y transformaciones recientes en la región vitivinícola argentina: Mendoza y San Juan, 1970-2005. Estudios sociales (Hermosillo, Son.), 16(31), 81-123.

Rocchi, F. (2005). Chimneys in the desert: industrialization in Argentina during the export boom years, 1870-1930. Stanford, California: Stanford University Press.

Román, J. A. S. (2013). Los argentinos y los impuestos: lazos frágiles entre sociedad y fisco en el siglo XX. Buenos Aires: Siglo Veintiuno Editores.

Romano, S. (1992). Finanzas públicas de la provincia de Córdoba 1830-1855. Boletín del Instituto Ravignani, 6.

Sánchez, G. (2015). Desigualdades regionales en la Argentina de la Belle Époque (1869-1914). Ensayos de Economía, 25(46), 45.

Sánchez Román, J. A. (2005). La industria azucarera en Argentina (1860-1914). El mercado interno en una economía exportadora. Revista de Indias, 65(233), 147-172.

Santilli, D. V. (2010). El papel de la tributación en la formación del Estado. La contribución directa en el siglo XIX en Buenos Aires. América Latina en la historia económica (33), 30-63. 
Schaller, E. C. (2012). La política en los espacios subnacionales. Provincias y territorios en el nordeste argentino (1880-1955). (M. S. Leoni y M. del M. S. Carnicer, Eds.). Rosario: Prohistoria Ediciones.

Schmit, R. (2008). Historia del capitalismo agrario: Los límites del progreso: expansión rural en los orígenes del capitalismo rioplatense, Entre Ríos 1852-1872. Buenos Aires: Siglo XXI Editores.

Solberg, C. E. (1985). Land Tenure and Land Settlement: Policy and Patterns in the Canadian Prairies and the Argentine Pampas, 1880-1930. En Argentina, Australia and Canada (pp. 53-75). Berlín: Springer.

Somoza, J. L. (1973). La mortalidad en la Argentina entre 1869 y 1960. Desarrollo Económico, 12(48), 807-826.

Willebald, H. (2007). Desigualdad y especialización en el crecimiento de las economías templadas de nuevo asentamiento, 1870-1940. Revista de Historia Económica/Journal of Iberian and Latin American Economic History (Second Series), 25(2), 293-347. 